\title{
Thermal Management System for Particle Sensors Design, Performance and Verification
}

\author{
Andreas Larsson, Olav Storstrom, Torleif Tollefsen Seip, Magnus Hjelstuen, \\ Robert Bjorklund, Anita Lloyd Spetz, Mats L Johansson, Ann Grant, Peter Jozsa, \\ Per-Erik Faegerman, Jaska Paaso and Lars Hammarlund
}

\section{Linköping University Post Print}

N.B.: When citing this work, cite the original article.

C2012 IEEE. Personal use of this material is permitted. However, permission to reprint/republish this material for advertising or promotional purposes or for creating new collective works for resale or redistribution to servers or lists, or to reuse any copyrighted component of this work in other works must be obtained from the IEEE.

Andreas Larsson, Olav Storstrom, Torleif Tollefsen Seip, Magnus Hjelstuen, Robert Bjorklund, Anita Lloyd Spetz, Mats L Johansson, Ann Grant, Peter Jozsa, Per-Erik Faegerman, Jaska Paaso and Lars Hammarlund, Thermal Management System for Particle Sensors Design, Performance and Verification, 2012, IEEE Sensors Journal, (12), 6, 22992305.

http://dx.doi.org/10.1109/JSEN.2012.2185044

Postprint available at: Linköping University Electronic Press

http://urn.kb.se/resolve?urn=urn:nbn:se:liu:diva-77857 


\title{
Thermal Management System for Particle Sensors - Design, Performance and Verification
}

\author{
Larsson A, Storstrom O, Seip T A T, Hjelstuen M \\ Instrumentation dept. \\ SINTEF ICT \\ NO-0373, Oslo, Norway \\ andreas.larsson@sintef.no
}

\author{
Johansson M L \\ Dept. 97621 PV3 C1 \\ Volvo Car Corp. \\ SE-40531, Göteborg, Sweden
}

\section{Fägerman P E}

Mandalon Technologies AB

SE-58112, Linköping, Sweden

\author{
Bjorklund R, Lloyd Spetz A \\ Dept. Physics, Chemistry and Biology \\ Linköping University \\ SE-58183, Linköping, Sweden
}

\author{
Grant A, Jozsa P \\ Dept 06100 \\ Volvo Technology Corp \\ SE-41288, Göteborg, Sweden
}

\author{
Paaso J \\ Selmic Oy \\ FI-90550, Oulu, Finland
}

\author{
Hammarlund L \\ SenSiC \\ SE-16440, Kista, Sweden
}

\begin{abstract}
This paper presents the thermal performance of a proposed thermal management device (patented in 2009) intended for a thermophoresis-based soot sensor. The performance was studied for temperatures ranging from $50^{\circ} \mathrm{C}$ to $400^{\circ} \mathrm{C}$ and for exhaust speeds up to $10 \mathrm{~m} / \mathrm{s}$. It also presents the design and basic concepts. The performance study and design development was performed with finite element analysis (FEA). The FEA results were then verified with experiments in a heated wind tunnel. The relative performance of the device was found to increase for higher temperatures and lower wind speeds. The main conclusion drawn from this study was that it is feasible to cool a sensor surface enough for a thermophoresis-based soot sensor in a diesel exhaust system.
\end{abstract}

Index Terms-Thermal management, Soot sensor, exhaust monitoring, FEA

\section{INTRODUCTION}

Emission regulations for the automotive industry have become more restrictive and demanding the last decades. The proposed California Code of Regulations Title 13, Section 1971.1.e.8 requirement for on board diagnostics (OBD) says that after model year 2013, all types of deterioration or failures in diesel particle filters must be detected before tailpipe emissions exceed a threshold value. This will require new types of monitoring techniques most likely involving particle

NICe (Nordic Innovation Centre) in Oslo, Norway - Project No. 09044I

VINNOVA, (the Swedish Agency for Research and Innovation),

Stockholm, Sweden - Project No. 2009-02887

VINN Excellence Centre FunMat, (Functional Nanoscale Materials) at

Linköping University and Industrial Partners sensors [1]. Soot collection can be performed by several mechanisms such as diffusion, impact and thermophoresis. Thermophoresis is a weak force asserted on aerosol nanoparticles $<100 \mathrm{~nm}$ in diameter when located in a temperature gradient. Collisions with more energetic gas molecules from the warmer zone result in a net movement toward the colder area. Thus the ability to maintain the sensor surface at a lower temperature than the ambient exhaust enhances the thermophoretic contribution to the soot deposition and vice versa. In other words, a wider temperature difference between the sensor surface and the ambient gas increases the sensor performance[2]. Hence, a main challenge is to generate a cold sensor surface in an otherwise hot environment.

Soot detection by the collection/resistance measurement technique makes use of the electrical conducting properties of the soot [3][4][5].

A new and innovative way of managing the temperature of a sensor device protruding into hot gas flows was proposed and patented in 2009 [6][7][8]. The concept consists of a closed thermally conductive pipe, sealed at both ends. Through the pipe a ceramic substrate, containing a finger electrode sensor structure at its end, penetrates into the hot

An earlier version of this paper was presented at the $2010 \mathrm{IEEE}$ SENSORS Conference and was published in its proceedings. 
flow. The generic idea is based on relative thermal conduction of different heat paths in the system.

This concept design has been further developed in this study. The study evaluates the design and performance of a novel thermal management system, especially its low temperature characteristics (about $100{ }^{\circ} \mathrm{C}$ ). Low temperature performance is the key issue for the proposed design. The generic properties are limited by the temperature difference between the exhaust and the ambient (2). This in combination with a requested temperature difference between the exhaust and sensor surface in the order of $50-70{ }^{\circ} \mathrm{C}$ [7] calls for an efficient design. The larger the temperature difference, the higher sensitivity of the soot sensor. Finite element analysis (FEA) was used for the design development process and performance study. Wind tunnel experiments were performed for verification of the FEA results.

The governing hypothesis for this study was:

It is possible to design a passive thermal management system for a diesel exhaust system that is able to cool a sensor surface enough for a thermophoresis based soot sensor.

The resulting temperature gradients were found to be in the feasible magnitude order for a thermophoresis based sensor.

An important conclusion from this study is that it is possible to efficiently cool a sensor or electronic device in a gas flow of temperatures between $100-600^{\circ} \mathrm{C}$.

\section{MATERIALS AND METHODS}

\section{A. Device design}

The thermal management system is shown in Figure 1. It consists of a $140 \mathrm{~mm}$ long heat shield (A) made of a sealed copper pipe with $2 \mathrm{~mm}$ wall thickness and $12 \mathrm{~mm}$ outer diameter. A $1 \mathrm{~mm}$ thick and $5 \mathrm{~mm}$ wide sensor substrate (B) made of 96\% alumina (both with and without glazing) penetrates from the exterior into the exhaust through the heat shield. A thick film resistive finger electrode structure (the sensor) is located at the end (C). The sensor may also be partly covered with a copper cap (D), only exposing the sensor surface to direct contact with the exhaust. The inside of the container is filled with air (E). For clarity, (A, D and E) will from this point on be referred to as the 'thermos' and (A-E) as the 'sensor device'. A $10 \mathrm{~mm}$ thick multi layer of aluminum oxide ceramic paper (F) is used to insulate the thermos from the exhaust pipe walls $(\mathrm{G})$. The exterior end of the device is submerged into a temperature controlled flow of water $(\mathrm{H})$.

This design provides the incoming heat (h) with four principal heat paths; $\left(\mathbf{h}_{\mathbf{1}}\right)$ conduction through the heat shield, $\left(\mathbf{h}_{2}\right)$ into and through the sensor substrate, $\left(\mathbf{h}_{\mathbf{3}}\right)$ through the insulation and $\left(\mathbf{h}_{4}\right)$ by conduction and convection through the encapsulated air. Radiation will also contribute some to the heat transfer between different parts.

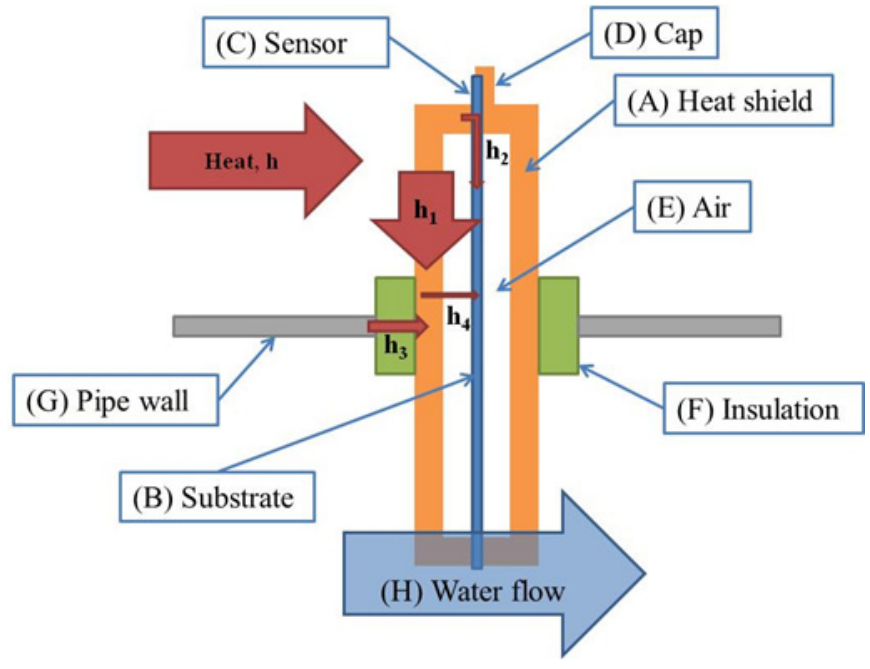

Figure 1. Device design

\section{B. Concept outline}

The basic idea of the design is to provide the incoming heat from the exhaust with an alternative heat path away from the sensor substrate. The theory of thermal resistance (similar to Ohm's law in electrical theory) states that heat will flow primarily along the path of lowest thermal resistance, if presented with a parallel path:

$$
q=\Delta T\left[\frac{1}{R_{1}}+\frac{1}{R_{2}}\right],
$$

where $\mathrm{q}$ is the heat transfer rate, $\Delta \mathrm{T}$ is the difference in inlet and outlet temperature, while $R_{1}$ and $R_{2}$ are the thermal resistance of two parallel heat paths for the heat flow. Thermal resistance may be defined as:

$$
R=\frac{\Delta T}{q}
$$

The conduction thermal resistance is:

$$
R_{\text {cond }}=\frac{L}{k A}
$$

where $R_{\text {cond }}$ is the thermal resistance, $L$ is the length of the conductor, $\mathrm{k}$ is the thermal conductivity and $\mathrm{A}$ is the cross-sectional area of the conductor.

Furthermore, the convective thermal resistance, $\mathrm{R}_{\text {conv }}$, can be written:

$$
R_{\text {conv }}=\frac{1}{h A}
$$

Where $\mathrm{h}$ is the heat transfer coefficient and $\mathrm{A}$ is the vetted surface area. This relation also applies to radiation heat transfer (for moderate temperatures) [9]. 


\section{Finite element model}

The FEA was performed with COMSOL Multiphysics 4.0 utilizing the optional 'heat transfer' module package. FEA was used during the complete design process.

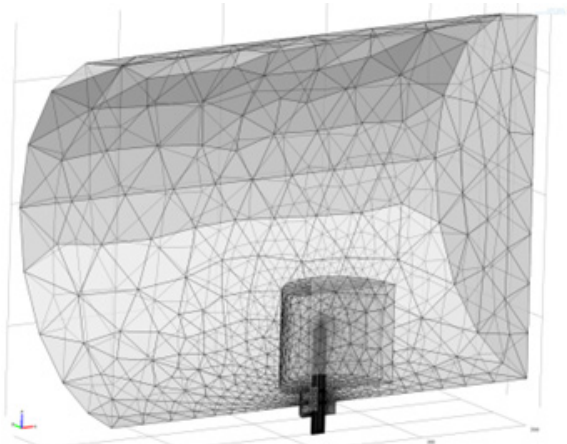

Figure 2. Typical mesh used for the FEA.

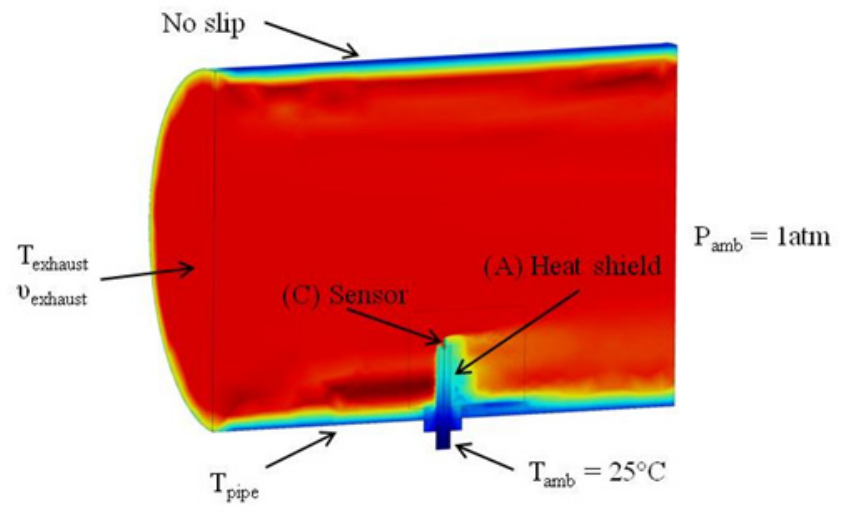

Figure 3. Typical BC used for the FEA.

TABLE I. MATERIAL PROPERTIES FOR FINITE ELEMENT MODELS

\begin{tabular}{|c|c|c|c|c|c|c|}
\hline Part & $\begin{array}{c}\text { Density } \\
\rho[\mathrm{kg} / \mathrm{m} 3]\end{array}$ & $\begin{array}{c}\text { Thermal } \\
\text { Conductivity } \\
\text { k [W/(mK)] }\end{array}$ & $\begin{array}{l}\text { Heat capacity } \\
\text { Cp }[\mathrm{J} /(\mathrm{kgK})]\end{array}$ & $\begin{array}{c}\text { Ratio of } \\
\text { specific heat } \\
\gamma\end{array}$ & $\begin{array}{l}\text { Dynamic } \\
\text { viscosity } \\
\mu\left[\mathrm{Pa}^{*} \mathrm{~s}\right]\end{array}$ & $\begin{array}{c}\text { Surface } \\
\text { emissivity } \\
\varepsilon\end{array}$ \\
\hline Adhesive & 2650 & 0.72 & 1000 & - & - & - \\
\hline Substrate & 3750 & $20^{\mathrm{a}}$ & 900 & - & - & $0.05 / 0.95$ \\
\hline Heat shield & 8960 & 401 & 384 & - & - & $0.5^{\mathrm{a}}$ \\
\hline Insulation & 192.1 & $0.06^{\mathrm{a}}$ & 1046.7 & - & - & - \\
\hline Exhaust/Air & $1.2^{\mathrm{a}}$ & $0.03^{\mathrm{a}}$ & $1020^{\mathrm{a}}$ & 1.4 & $1.8-5^{\mathrm{a}}$ & - \\
\hline
\end{tabular}

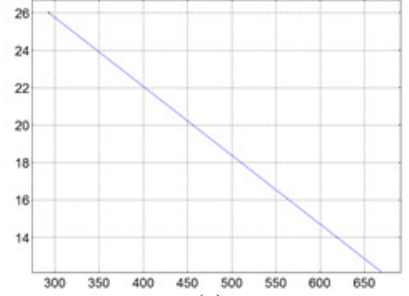

(a)

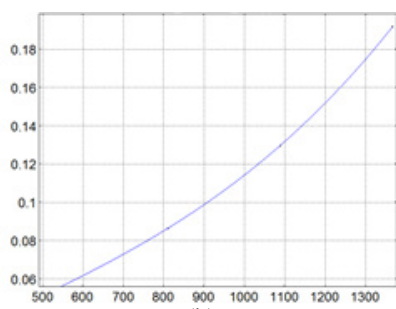

(b)

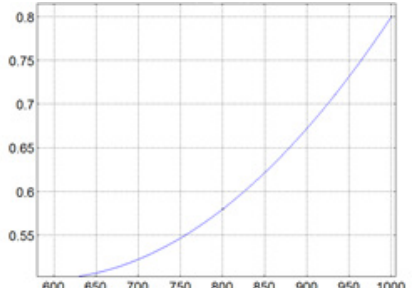

(c)

Figure 4. Non constant material properties used for FEA.

(a)-Thermal conductivity for substrate; $\mathrm{x}$-axis: Temperature $[\mathrm{K}], \mathrm{y}$-axis: Thermal conductivity $[\mathrm{W} /(\mathrm{mK})]$

(b)-Thermal conductivity for insulation; $\mathrm{x}$-axis: Temperature $[\mathrm{K}], \mathrm{y}$-axis: Thermal conductivity $[\mathrm{W} /(\mathrm{mK})]$

(c)-Emissivity for heat sink $\mathrm{x}$-axis: Temperature [K], $\mathrm{y}$-axis: Emissivity

\section{a) Physical conditions}

Typical operating temperatures and flow rates for diesel exhaust is up to about $300{ }^{\circ} \mathrm{C}$ and $7,9 \mathrm{~m} / \mathrm{s}$ [7]. The flow may be either laminar or turbulent for this type of system, depending on Reynolds number [7]. The flow characteristics were modeled with compressible flow with the $\mathrm{k}-\varepsilon$ turbulence model. To reduce model size, symmetry was used. The pipe wall was excluded from the model to further reduce model size, since it is not significant for the results for this type of system [7]. All models were modeled as quasi-stationary systems.
TABLE II. COMBINATIONS OF BOUNDARY CONDITIONS FOR EXHAUST AND PIPE TEMPERATURES

\begin{tabular}{ccccccccc}
\hline Location & \multicolumn{7}{c}{ Temperature $\left[{ }^{\circ} \mathbf{C}\right]$} \\
\hline Exhaust & 50 & 75 & 90 & 100 & 150 & 200 & 300 & 400 \\
Pipe & 20 & 30 & 36 & 40 & 60 & 80 & 120 & 160 \\
\hline
\end{tabular}

\section{b) Materials}

The material properties used for the finite element models (FEM) are presented in Figure 4 and TABLE I. Properties of air from COMSOL material library were used to model the exhaust and the air inside the thermos 


\section{c) Finite element model sensitivity}

The model sensitivity to mesh and materi parameters was checked for all models. Quadratic tetrahedral elements were used. A typical mesh is shown in Figure 2.

\section{d) Boundary conditions}

Typical boundary conditions (BC) used for the FEA are presented in Figure 3.

The pipe wall temperature was estimated to be between 20 ${ }^{\circ} \mathrm{C}$ and $160{ }^{\circ} \mathrm{C}$ during operation. The pipe and exhaust temperature combinations used are shown in TABLE II. The exhaust speeds were modeled from $0.01 \mathrm{~m} / \mathrm{s}$ up to $10 \mathrm{~m} / \mathrm{s}$ to investigate the forced convection properties of the system. One model was checked for presence of natural convection inside the thermos. Remaining models were modeled without the fluidic properties of air inside the thermos, i.e. without convection. Two models were modeled with radiation between heat shield and sensor substrate. The emissivity of the substrate were set to $\varepsilon=0.95$ and $\varepsilon=0.05$, representing a surface with high or low absorption of thermal radiation.

\section{Experimental study}

The experimental setup consisted of a flow loop, with a $300 \mathrm{~mm}$ inner diameter, possible of generating turbulent wind speeds up to $10 \mathrm{~m} / \mathrm{s}$ and gas temperatures extending from room temperature up to $300{ }^{\circ} \mathrm{C}$. The sensor device penetrated $65 \mathrm{~mm}$ into the pipe. The other end of the sensor device was placed into an adapter with a temperature controlled water flow. The water flow was used to control the external temperature and mimic the external forced convection cooling present in a real diesel exhaust system.

The temperature was measured with $0.2 \mathrm{~mm}$ thick, welded $\mathrm{K}$-type thermocouple elements. They were located (1) at the sensor or cap, (2) into the top of the heat shield, (3) into the heat shield $45 \mathrm{~mm}$ down the side from the sensor center and (4) inside the water flow at the thermos base.

All elements were attached with a thermally conductive ceramic adhesive based on alumina and ceramic binders. All elements were drilled into the bulk of the copper. The same adhesive were used to assemble the sensor substrate with the heat shield. The experiments were used as a verification of the FEA results.

The wind speeds were measured with two types of anemometers; one pitot tube (Testo 512) and one vane probe (Testo 416).

\section{RESULTS}

\section{A. Model sensitivity}

The used meshes were found to be adequate and no significant sensitivity to material parameters were found.

\section{B. Temperature distribution}

A plot of a typical temperature distribution for a sensor device with cap is shown in Figure 5. One can observe that the temperature is lower for the sensor substrate than for the heat shield at the same elevation above the pipe wall (approximately $5-10{ }^{\circ} \mathrm{C}$, depending on height above pipe wall).

\section{Sensor temperature as a function of exhaust speed}

\section{1) Finite element analysis}

The low temperature performance, $\mathrm{T}_{\text {exhaust }}=100{ }^{\circ} \mathrm{C}$, was investigated as a function of exhaust speed. In Figure 6, curves with a square root shape, dependent on flow speed, are shown.

Addition of fluidic properties for the encapsulated air inside the thermos resulted in a velocity field approximately zero. Hence, the sensor temperature changed less than $0.1 \%$, compared to an equivalent model without the fluidic properties.

\section{2) Experiments}

The experimental results were similar to the FEA results, both shape and magnitude order (Figure 6). The experiment showed lower sensor temperatures than the FEA for higher speeds.

\section{Thickness of heat shield}

One model was designed with the normally $2 \mathrm{~mm}$ heat shield thickness decreased to $1 \mathrm{~mm}$ (same inner radius) to study the system sensitivity to heat shield thickness or thermal resistance. The result was a significantly higher sensor temperature (Figure 6).

\section{E. Sensor temperature as a function of exhaust temperature}

\section{1) Finite element analysis}

The sensor temperature for different exhaust speeds and temperatures ranging between $0.01 \mathrm{~m} / \mathrm{s}$ to $7.9 \mathrm{~m} / \mathrm{s}$ and $50{ }^{\circ} \mathrm{C}$ to $400{ }^{\circ} \mathrm{C}$ is shown in Figure 7. A linear dependence was found. If the relative sensor temperature is plotted against exhaust temperature (Figure 8) one can see that the sensor temperature seems to approach a final fraction of the exhaust temperature.

\section{2) Experiments}

Similar observations were made for the experiments as for the FEA (Figure 7 and Figure 8).

\section{F. Sensor temperature as a function of protrusion depth}

\section{1) Finite element analysis}

The sensor temperature for different protrusion depths ranging from $3.5 \mathrm{~cm}$ to $10.5 \mathrm{~cm}$ is shown in Figure 9. The sensor temperature increased linearly as a function of increasing protrusion depth.

\section{2) Experiments}

Only one data point was recorded from the experiments. However, this fitted the FEA results well (Figure 9).

\section{G. Radiation}

Enabling thermal radiation between the heat shield and sensor substrate in the finite element program had no significant impact on the sensor temperature. The difference was found to be less than $\pm 1 \%$ for both models ( $\varepsilon=0.05$ and 
$\varepsilon=0.95)$ compared to an equivalent model without radiation enabled.

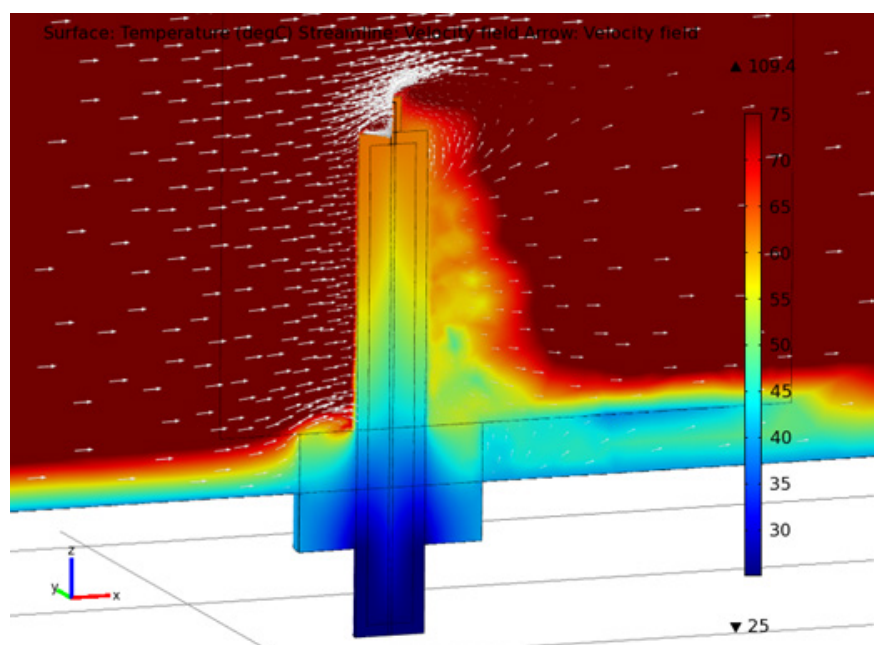

Figure 5. Temperature distrubution for thermos with cap for a $100^{\circ} \mathrm{C}$ exhaust flow at $7.9 \mathrm{~m} / \mathrm{s}$. White arrows vizualize the velocity field. $\mathrm{T}_{\text {sensor }} \approx 64^{\circ} \mathrm{C}$.

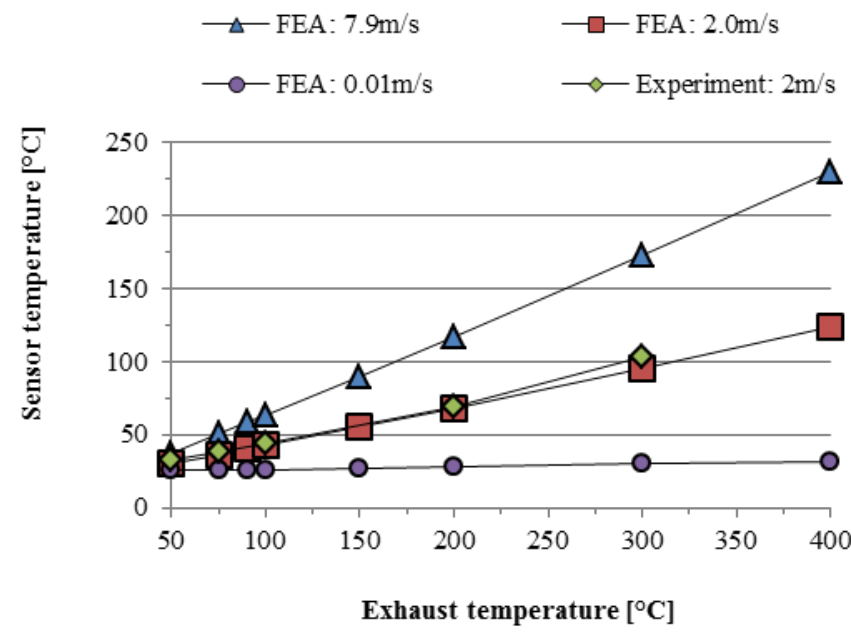

Figure 6. Sensor temperature as a function of exhaust speed for three different designs. The exhaust temperature was $100{ }^{\circ} \mathrm{C}$.

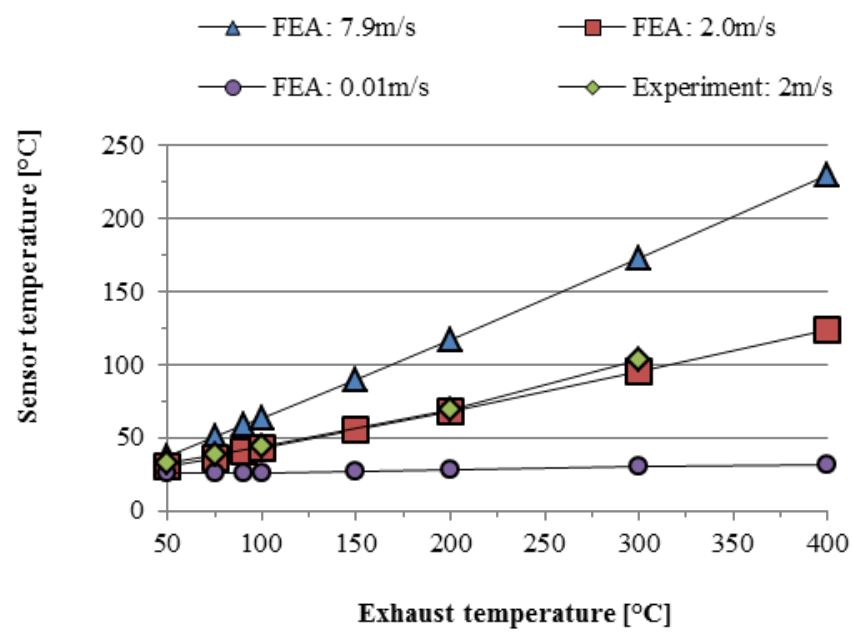

Figure 7. Sensor temperature as a function of exhaust temperature of a sensor device with a cap.

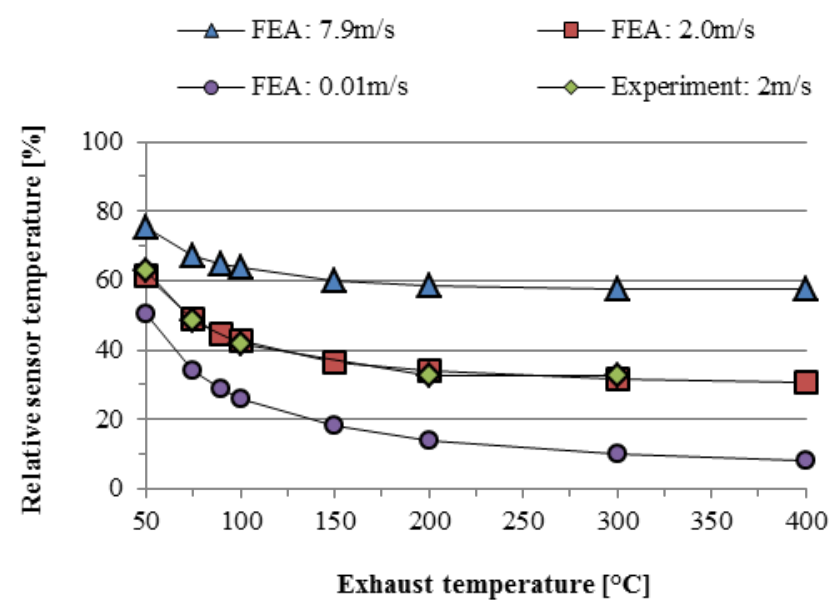

Figure 8. Relative sensor temperature as a function of exhaust temperature of a sensor device with a cap. Sensor temperature has been normalized to the exhaust temperature; $T_{\text {sensor }} / T_{\text {exhaust }}$.

$\longrightarrow$ FEA: $2.0 \mathrm{~m} / \mathrm{s} \quad \longrightarrow$ Experiment: $2.0 \mathrm{~m} / \mathrm{s}$

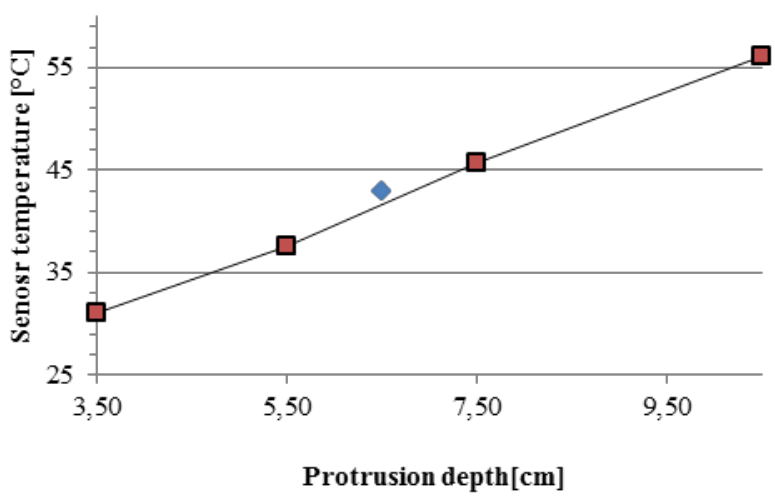

Figure 9. Sensor temperature as a function of protrusion depth. The exhaust speed was $2.0 \mathrm{~m} / \mathrm{s}$, while the exhaust temperature was $100^{\circ} \mathrm{C}$. 


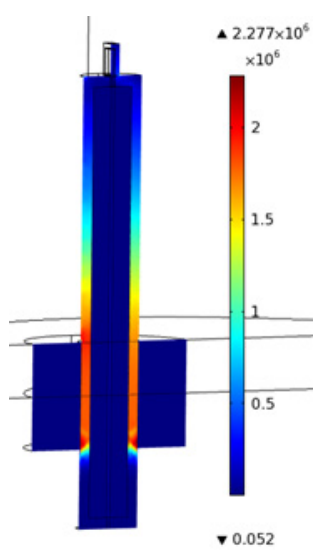

Figure 10. Total heat flux magnitude $\left(\mathrm{W} / \mathrm{m}^{2}\right)$ distribution for the sensor device.

\section{H. Heat transfer}

The majority of the total heat flux inside the sensor device was concentrated within the heat shield (Figure 10). The heat flux in the remaining volume of the sensor device is kept to less than a few percent of the total heat flux.

\section{DISCUSSION}

\section{A. Sensor temperature as a function of exhaust speed}

\section{1) Finite element analysis}

The cooling performance of the device is significantly better at lower exhaust speeds than at higher (Figure 6), due to the reduced heat transfer coefficient for the forced convection at lower speeds. The sensor temperature was found to be within the requested range of $50-70{ }^{\circ} \mathrm{C}$ below exhaust temperature, for speeds up to $2-4 \mathrm{~m} / \mathrm{s}$ (with and without cap). Addition of the cap improved the performance significantly by reducing the sensor temperature by about 10 ${ }^{\circ} \mathrm{C}$. The cap functions as a small local heat shield which limits the exposed area of the protruding substrate to the hot gases. It also functions as an extended heat path of the heat shield semi encapsulating the sensor tip of the substrate.

Natural convection is prohibited by the orientation of the device. E.g., a vertically assembled sensor device with the cooling at the upper end would most likely show presence of natural convection, hence reducing its cooling performance.

\section{2) Experiments}

The cooling performance of the tested device was found to be sufficient for speeds up to $5 \mathrm{~m} / \mathrm{s}$, which is slightly higher than for the FEA results. The device seems to exhibit a better performance in the experiments, especially for higher flow rates, than that predicted by the FEA analysis (Figure 6). These deviations are well within the margin of error for the experiments. Especially, we have a high uncertainty in our wind speed measurements, and so the experimental results may lie closer to the FEA predictions.

\section{B. Thickness of heat shield}

Increasing the thickness of the heat shield significantly improved the thermal performance of the system (Figure 6). The sensor temperature dropped with about $20{ }^{\circ} \mathrm{C}$. This is because the thermal resistance for a conductor, e.g. the heat shield, is dependent of its cross-sectional area (3). Since the increased thickness increases the area it also reduces the thermal resistance. This increases the relative difference in thermal resistance between different heat paths e.g. $\left(\mathbf{h}_{\mathbf{1}}\right)$ and $\left(\mathbf{h}_{2}\right)$ in Figure 1, hence a larger fraction of the heat flux is guided through the heat shield (1).

\section{Sensor temperature as a function of exhaust temperature}

\section{1) Finite element analysis}

For the low flow rate, the cooling performance was found to be sufficient for exhaust temperatures above $75^{\circ} \mathrm{C}$ (Figure 7). For the high flow rate it was sufficient for exhaust temperatures above $130{ }^{\circ} \mathrm{C}$. The observed linear behavior is still under investigation. One interesting observation in Figure 8 is that all curves seem to approach a final level e.g. the $3.0 \mathrm{~m} / \mathrm{s}$ curve is approaching a sensor temperature of about $37 \%$ of the exhaust temperature. The knees of the curves also seem to be more pronounced and shift to the left for higher speed. Another observation is that the efficiency of the system is increasing with increasing exhaust temperature after the threshold value. The nature of this threshold is still under investigation.

\section{2) Experiments}

Figure 7 and Figure 8 demonstrates good correlation between FEA results and experiments.

\section{Sensor temperature as a function of protrusion depth}

\section{1) Finite element analysis}

An increase in protrusion depth increases the sensor temperature (Figure 9). The sensor temperature increased approximately $25{ }^{\circ} \mathrm{C}$ for a protrusion depth increase of 7.0 $\mathrm{cm}$. This is because the thermal resistance for a conductor, e.g. the thermos, is linearly dependent of its length (3). An increase in protrusion length, e.g. the length of the device, will therefore give an increased thermal resistance, and hence the sensor temperature will increase.

\section{2) Experiments}

In Figure 9 a good correlation between FEA results and experiments is shown.

\section{E. Heat transfer}

From Figure 10 one can see that the heat shield works as intended i.e. providing a low thermal resistance heat path away from the sensor. It is also possible to see that the principal path of heat flow was through the heat shield in the vertical direction (parallel to the center axis of the heat shield).

\section{F. Radiation}

The limited contribution of radiation between the heat shield and the substrate is due to the rather low absolute 
temperatures and small temperature differences for adjacent surfaces, hence generating a negligible net energy transfer.

\section{G. Wind speed measurements}

The wind speed measurements performed with the pitot tube correlated better with the FEA results than the ones with the vane probe. The pitot tube showed wind speeds about two thirds that of the vane probe. This results in worse performance data for the pitot tube measurements than for the vane probe readings. Results presented in Figure 6 to Figure 8 are based on wind speeds measured with the pitot tube. The uncertainty of the measurements is high due to fluctuation in the readings, about $\pm 20 \%$ and because of the turbulent nature of the flow inside the wind tunnel. An estimated average value was used as the "measured" value.

\section{H. General remarks}

The results presented here agree well with previous findings presented in [7].

Further work includes measuring and improving the transient response of the system. A thick copper heat shield is efficient from a thermal resistance point of view, but the added thickness also provides more mass to the system, hence limiting the transient response, i.e. impede its thermal impedance performance.

Another point of future investigation is the performance as a function of protrusion of the device into the exhaust. Deeper penetration into the flow is expected to reduce the performance significantly, with consequences such as design changes, e.g. geometry and material choice, to achieve the requested temperature levels of the sensor.

With the presented type of thermal management system it is possible to design a solution that may control the local temperature of a sensor or electronic device protruding into a thermally harsh fluid environment. The applications of this type of system may be e.g. to cool a component or perhaps to heat it up, when exposed to a harsh environment.

If a feedback system with active cooling/heating is added to the device, a system able to actively control and monitor the local temperature of a sensor or electronics is feasible.

The proposed type of solution may be utilized within several different industries e.g. process, oil, space, aerospace, as well for the automotive industry. Examples of applications of the thermal management presented here are: thermophoresis-based gas/particle detectors and calibration and temperature control of temperature sensitive sensors or components.

\section{CONCLUSION}

We draw the conclusion that it is feasible to cool a thermophoresis-based sensor device enough for efficient soot deposition, provided that a relatively cold place is present nearby. The proposed thermal management solution is dependent of both gas speed and temperature. Its relative performance is better for higher exhaust temperatures and lower speeds. Achievable local temperatures will be limited by the available temperature difference between exhaust and ambient.

\section{ACKNOWLEDGMENT}

The authors would like to thank all contributors to this study; project members, colleagues and the grant agencies (see first page).

\section{REFERENCES}

[1] R. Bjorklund et al., "Resistance Sensor Based on Thermophoresis for Soot in Diesel Exhaust", MRS Spring Meeting, 2010

[2] A. Messerer, R. Niessner and U. Pöschl, "Thermophoretic deposition of soot aerosol particles under experimental conditions relevant for modern diesel engine exhaust gas systems", Journal of Aerosol Science, 2003, 34(8), 1009-1021

[3] M. Fleischer, R. Pohle, K. Wiesner and H. Meixner, "Soot sensor for exhaust gases", Eurosensors XIX, , 2005

[4] G. Hagen, C. Feistkorn, S. Wiegärtner, A. Heinrich, D. Brüggemann and R. Moss, "Conductometric Soot Sensor for Automotive Exhausts: Initial Studies", Sensors 2010, 10, 1589-1598

[5] D. Lutic et al., "Detection of Soot Using a Resistivity Sensor Device Employing Thermophoretic Particle Deposition", Journal of Sensors, Vol. 2010, Article ID 421072, 6 pages, doi:10.1155/2010/421072

[6] A. Larsson, "Lokal termisk styring", Norwegian Industrial Property Office, Application No.: 20092713, 2009.07.20

[7] A. Larsson and Oldervol F, "Thermal modelling of a thick film based soot sensor for automotive applications", Proc. of iMAPS Nordic, 2009

[8] A. Malik, H. et al., " A Potential Soot Mass Determination Method from Resistivity Measurement of Thermophoretically Deposited Soot", Aerosol Science and Technology, Vol. 45, Issue 2, pp. 284-294, 2011

[9] T.L.Bergman, A.S.Lavine, F.P.Incropera and D.P.Dewitt, Fundamentals of Heat and Mass transfer, John Wiley \& Sons, Inc., 2011. 